\title{
Testing of bearing materials for large two-stroke marine diesel engines
}

\author{
Vølund, Anders; Klit, Peder; Persson, Sebastian
}

Published in:

Proceedings of the Institution of Mechanical Engineers, Part J: Journal of Engineering Tribology

Link to article, DOI:

10.1177/1350650115597462

Publication date:

2017

Document Version

Peer reviewed version

Link back to DTU Orbit

Citation (APA):

Vølund, A., Klit, P., \& Persson, S. (2017). Testing of bearing materials for large two-stroke marine diesel engines. Proceedings of the Institution of Mechanical Engineers, Part J: Journal of Engineering Tribology, 231(4), 503-508. https://doi.org/10.1177/1350650115597462

\section{General rights}

Copyright and moral rights for the publications made accessible in the public portal are retained by the authors and/or other copyright owners and it is a condition of accessing publications that users recognise and abide by the legal requirements associated with these rights.

- Users may download and print one copy of any publication from the public portal for the purpose of private study or research.

- You may not further distribute the material or use it for any profit-making activity or commercial gain

- You may freely distribute the URL identifying the publication in the public portal 


\title{
Testing of Bearing Materials for Large Two-stroke Marine Diesel Engines
}

\author{
Anders Voelund ${ }^{1 *}$, Peder Klit ${ }^{2}$, Sebastian Persson ${ }^{1}$ \\ ${ }^{I}$ MAN Diesel \& Turbo SE, Teglholmsgade 41, 2450 SV Copenhagen, Denmark. \\ ${ }^{2}$ DTU, Department of Mechanical Engineering, Nils Koppels Alle 404, 2800 Lyngby.
}

\begin{abstract}
In large two-stroke marine diesel engines bearings are designed to last the lifetime of the engine. The design has shown very good service experiences. The design parameters of the main bearings are, among others, based on the average maximum specific load which the bearing should operate under. In general, the frictional loss is less than $1 \%$ of the nominal power of the engine but is still a target for optimization. Fatigue mechanisms of bearing lining material are not fully understood and the design limits with regards to minimum oil film thickness, max oil film pressure and oil film pressure gradient is not established. Large two-stroke journal bearings are not suitable for fatigue test due to the size, the low rotational speed and the complexity of such a test-rig. The Disc Fatigue Test Rig (DFTR) was designed with the purpose to test white metal coatings under realistic bearing conditions, in a confined time-frame. The test-rig simulates a scale model of a thrust bearing, in contrary to standard design the bearing lining material is applied to the rotating collar. Parameters, such as bearing load, rotational speed, oil temperature, oil contamination is controlled/monitored in order to achieve repeatability and a systematic approach to the experiments. Test performed on the test-rig shows good correlation on the fatigue cracks with those experienced on large two-stroke journal bearings.
\end{abstract}

Keywords: Fatigue, White Metal, Damage, Oil Film Pressure, Test Rig.

*Corresponding author: Anders Voelund, anders.voelund@man.eu.

\section{INTRODUCTION}

Bearings for large two-stroke marine diesel engines are typically in service for the entire lifetime of the engine - up to 20-30 years is not unusual service life (Figure 1). The bearing shell is installed in the engine and firmly positioned by the design of the structure surrounding the bearing. The design of these bearings is to a large extend based on empirical knowledge in combination with simulations. These simulation results are compared to basic design rules and thus assisting in the validation of new designs. The typical white metal bearing shell, consist of a base material (steel) on which the white metal has been applied.

Traditionally bearings installed in MAN Diesel \& Turbo SE (MDT) engines were equipped with white metal as bearing lining. This mindset changed years back when certain bearings in certain engines started to show less good performance due to fatigue cracks at bearing edges. This required a modification in order to address this issue. The solution was the introduction of the AlSn40 bearing - a steel lining with an AlSn40 roll bonded on top as bearing lining. The fatigue properties of this bearing shell in somewhat superior to a conventional white metal bearing, which has also been demonstrated by the service experiences with this bearing type. A drawback of this bearing type is the reduced capability to operate under extreme conditions. From time to time failures occur. These failures may originate from e.g. foreign particles, water in oil, poor quality in the production process, erroneous installation. The reduced capability to operate under extreme conditions can lead to engine failures, where major components (Engine structure or crankshaft) needs to be replaced or re-machined. This is typically not the case for engines fitted with white metal main bearings.

The introduction of more sophisticated simulation tools has helped MDT to increase acceptable nominal load on the main bearings. At the same time more understanding of which parameters that affect the performance such as minimum oil film thickness and maximum oil film pressure has led to new designs. 
The „Blended Edge" (Figure 2) design compared to the conventional design increased the minimum oil film thickness significantly thus enabling the possibility to re-introduce the white metal bearing, with its superior tribological properties. Having this in mind there is still a need for understanding the mechanisms in relation to fatigue of white metal bearings.

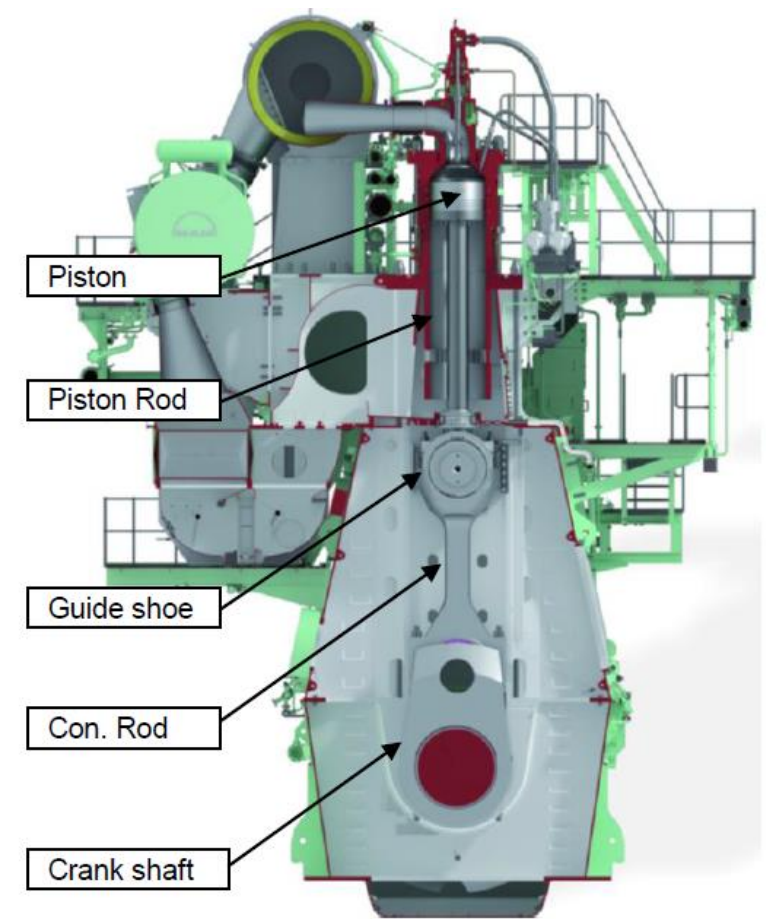

Figure 1: Cross Sectional View of Large Two-stroke Marine Diesel Engine (Important Components Highlighted)

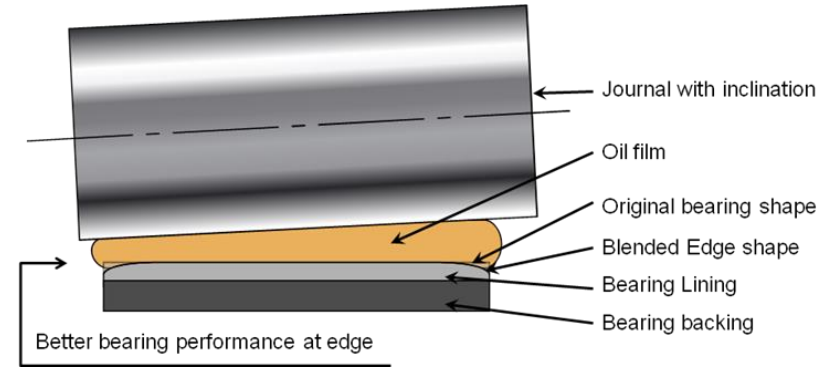

Figure 2: Bearing Design / Blended Edge

\section{TESTING OF WHITE METAL BEARING ALLOYS}

White metal fatigue tests are described in DIN 50100, 50113 and 50142 where compound material is tested with alternating tensile/compressive stress and rotating bending. This test is commonly used by bearing manufacturers to test the lining fatigue properties. But since the test is performed on specimens that have little in common with a thin bearing lining the test results cannot be transferred to plain bearings. In the last century plain bearing has been tested countless times on many designs of test rigs to simulate realistic bearing conditions. These kinds of test rigs tend to be complicated and repeatability is hard to achieve -e.g. ISO 7905. In an EC-collaboration project denoted 'Hercules- $\beta$ '- Rolf Koring from ECKA granulates developed a new fatigue test bench in collaboration with the Technical University Dusseldorf and MDT (Koring, 2013). The purpose of the test bench was to evaluate the fatigue properties of laser lined bearing linings under realistic conditions.

\section{DISC FATIGUE TEST RIG}

The Disc Fatigue Test Rig (DFTR) (Figure 3) was designed as a collaboration between The Technical University of Denmark (DTU) and MDT with the purpose to test white metal coatings under realistic bearing conditions, in a confined time-frame (Klit, 2013). The disc fatigue test rig has been developed in the EC-project 'Hercules-C'. The test disc consists of three parts, an upper and lower disc with lined white metal on the outer and a middle disc which is used to assemble the set of discs (Figure 3). The design allows for two tests with almost the same environment to be tested at the same time. The test-rig simulates a scale model of a thrust bearing. The purpose with this testrig is, through experimental analysis, to clarify some of the reasons and mechanisms for crack formation and growth in white metal coatings due to fatigue. With a better knowledge of bearing fatigue the bearings can be designed with lower friction losses.

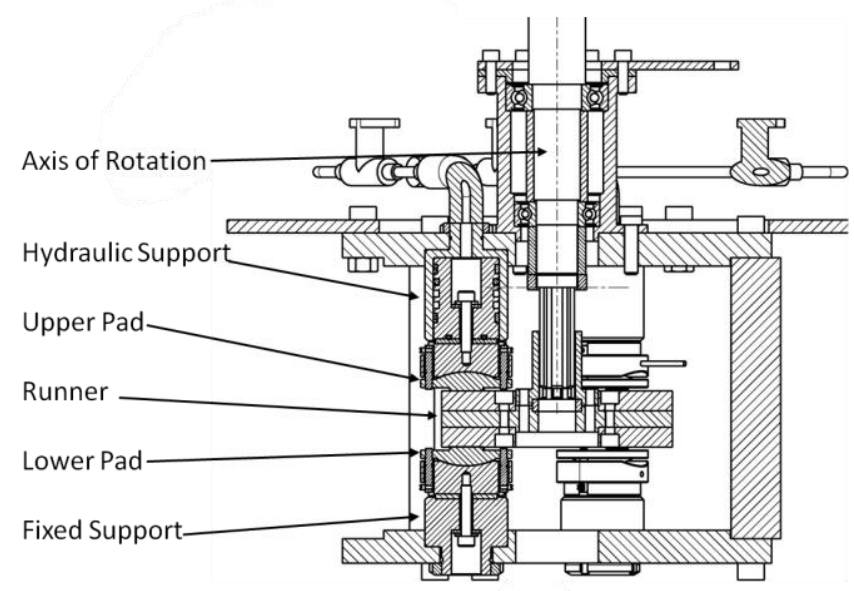

Figure 3: Cross section through assembly drawing showing the test specimens positioned in loading arrangement with Lower and Upper Pad pressed against the test specimens by hydraulic actuation. The test specimens (The Discs mounted on each side of the Runner) are connected to the drive shaft via a parallel spline connection allowing the runner with test discs to adjust in vertical position and to adapt for a small misalignment in the small gap between the disc and the splined hub. 
Further info can be seen found in (Klit, 2013) and

Figure 4

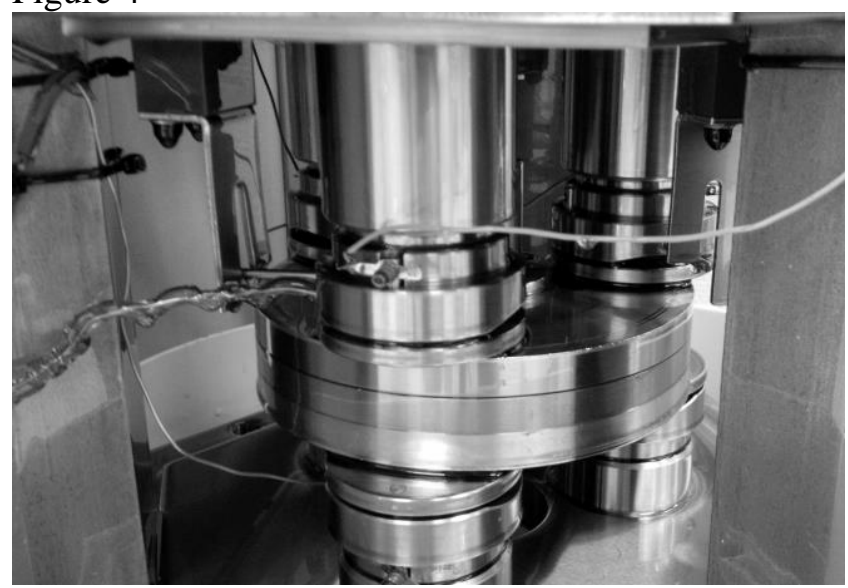

Figure 4: Physical Setup of the DFTR showing the disc and the three pads facing each white metal disc.

\section{MEASUREMENTS}

An experiment was carried out with the conditions shown in Table 1.

Table 1: The running conditions for the experiment reported on the DFTR

\begin{tabular}{|c|c|}
\hline Speed & $2500 \mathrm{rpm}$ \\
\hline Nominal Load & $42 \mathrm{MPa}$ \\
\hline Bulk Oil Temperature & $60 \mathrm{deg}$. C \\
\hline Thrust Piece Temperature & $95 \mathrm{deg}$. C \\
\hline Oil Type & SAE 30 \\
\hline Filtration Unit & CJC-Off-line \\
\hline Disc Type & Steel / White Metal \\
\hline No of Pads & 3 \\
\hline
\end{tabular}

The bulk temperature of the oil was controlled using a PID controller. The coefficient of friction was determined from a torque measurement. The temperature of the thrust piece was measured as well as the Electrical Resistance Measurement (ERM), (Voelund, 2010). The ERM principle is shown in Figure 5 and is basically a resistance measurement of the oil film in the gap between the runner and the pad. Each pad is electrically isolated from the disc thus making it possible to monitor when solid contact between a pad and the disc occurs The ERM was installed in order to have a simple system for indication of a system change (crack development). Since the oil film thickness between the thrust piece (each pad) and the collar (disc) was only a few microns wear particles can be detected to some extent using this rather simple setup (Eq.1).

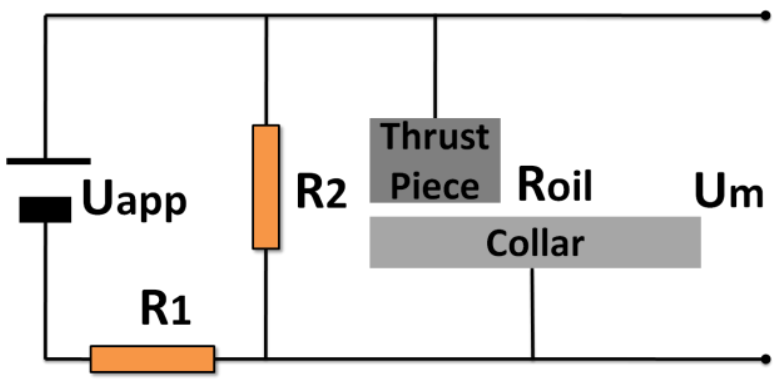

Figure 5: Schematic setup of the ERM - system.

$U_{m}=\frac{R_{2} R_{\text {oil }}}{R_{1}\left(R_{2}+R_{\text {oil }}\right)+R_{2} R_{\text {oil }}} U_{\text {app }}$

The disc was installed and the pressure in the loading system was gradually increased until the desired value mas measured. The nominal load applied was defined as the average pressure between one pad and the disc. The speed was kept constant during the experiment by the use of an angular encoder coupled with a frequency controlled $4 \mathrm{~kW}$ AC motor driving the system. The experiment was stopped every $0.2 \times 10^{6}$ cycles and a visual inspection was performed. The system was disassembled after $1 \times 10^{6}$ cycles for a complete inspection. During one revolution the white metal disc is subjected to three cycles of loading - one for each passage of the pad.

Nothing out of the ordinary was observed in the ERMsignal - see Figure 12. The same can be seen on the running surface, which is shown in Figure 6 and a close-up of one of the locations in Figure 9. After reinstalling the disc the experiment was resumed. Shortly after another $0.6 \times 10^{6}$ cycles an indication was observed on the ERM-signal - shown in Figure 13. Having extracted the disc the following general appearance was observed - see Figure 7. InFigure 7 the same area as chosen in Figure 9 was once again inspected in the microscope revealing the image shown in Figure 10. After re-installing the disc once more the system failed shortly after. The global count was now $2 \times 10^{6}$ cycles. The disc was now severely damaged see Figure 8 and the area of interest even more - see Figure 11. 


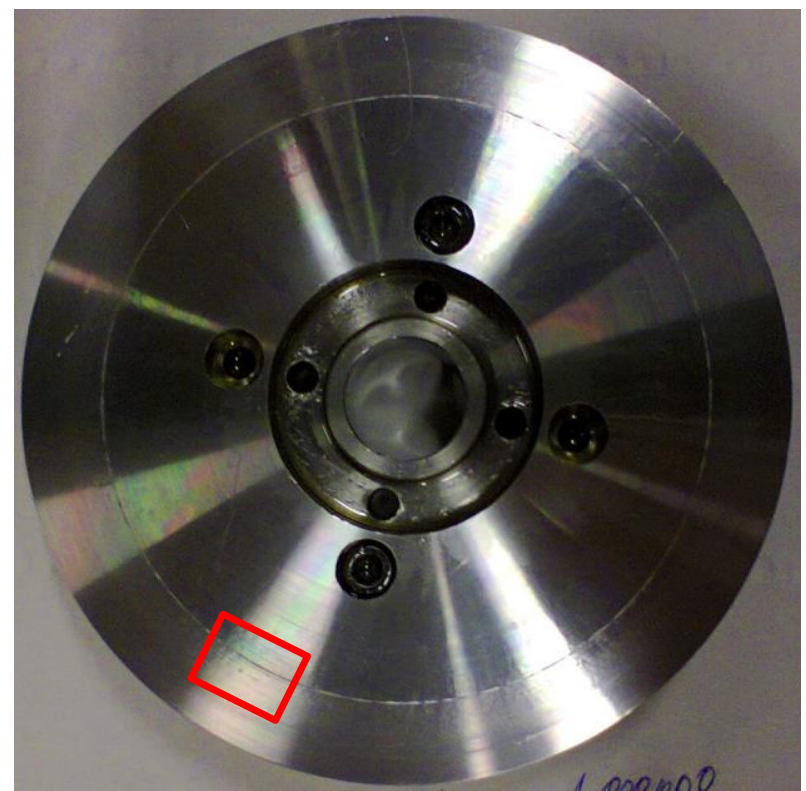

Figure 6: Disc after 1.0x10 cycle. The marked area is denoted 'Location A'.

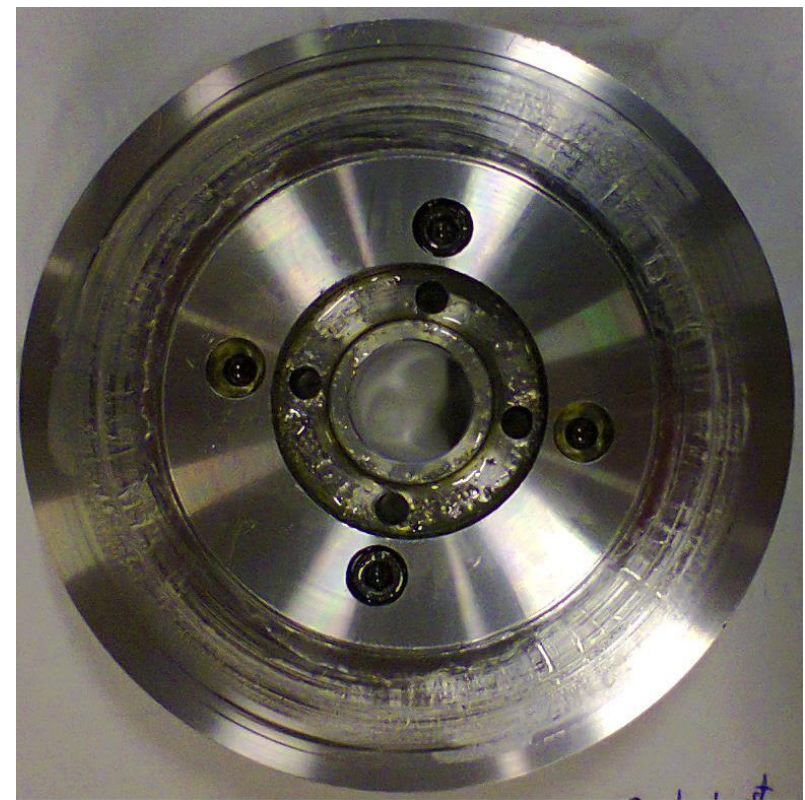

Figure 7: Disc after $1.6 \times 10^{6}$ cycles

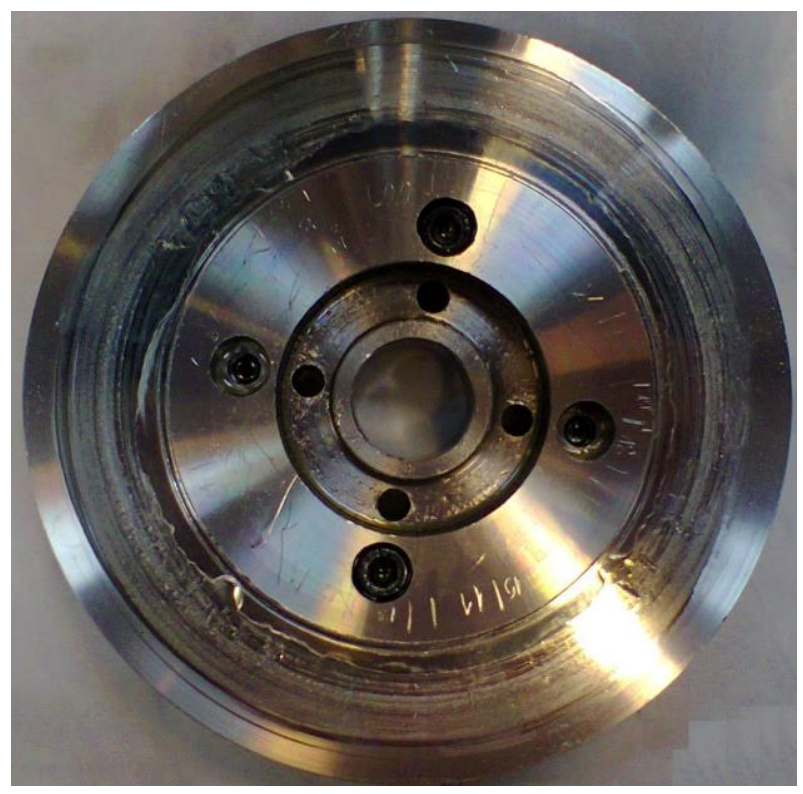

Figure 8: Disc after $2.0 \times 10^{6}$ cycles

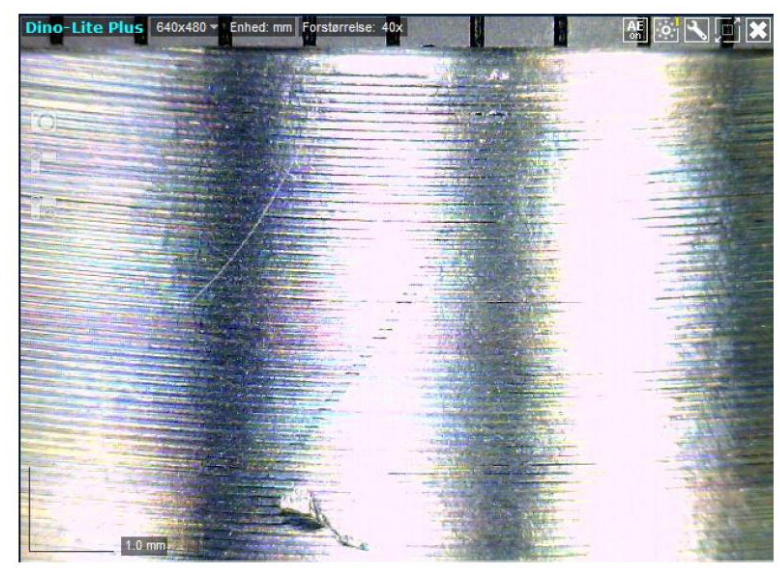

Figure 9: Close-up on disc in location A - possible crack on disc after $1.0 \times 10^{6}$ cycles.

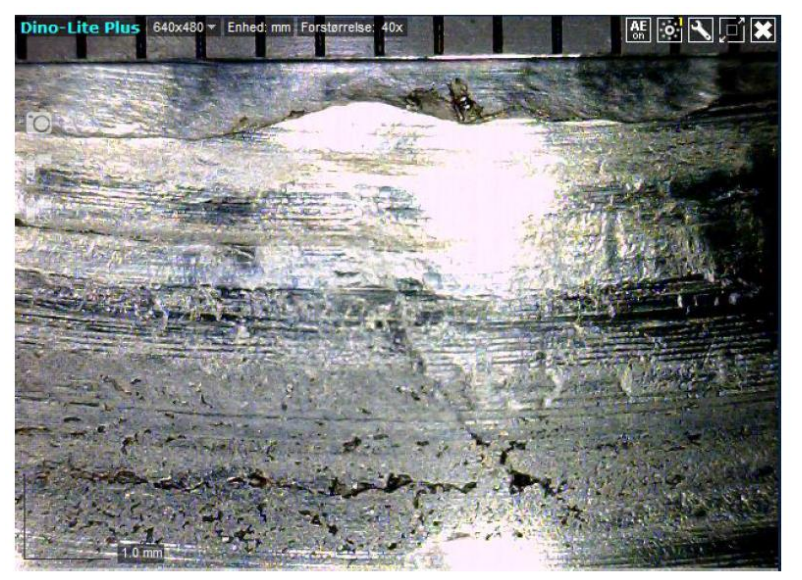

Figure 10: Close-up of location A after $1.6 \times 10^{6}$ cycles now showing damaged surface. Both cracks and smearing of the white metal surface can be observed. 


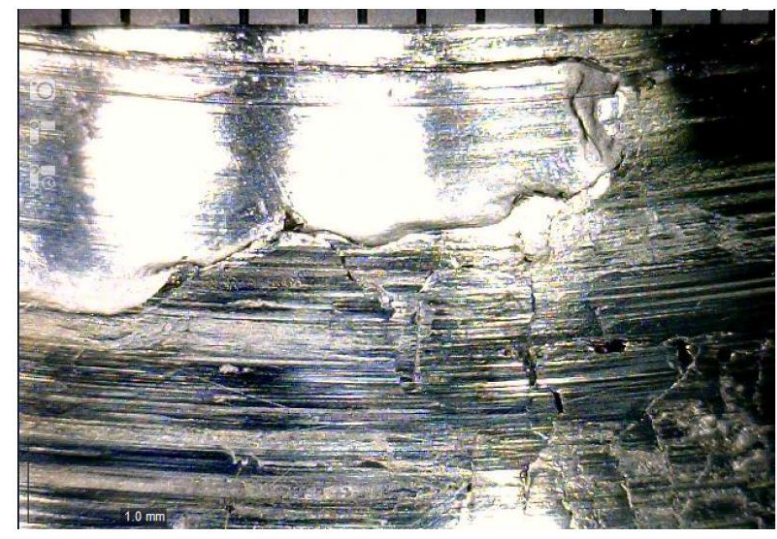

Figure 11: Close-up of location A after 2.0x10 ${ }^{6}$ cycles now showing severely damaged surface. Both cracks and smearing of the white metal surface can be observed

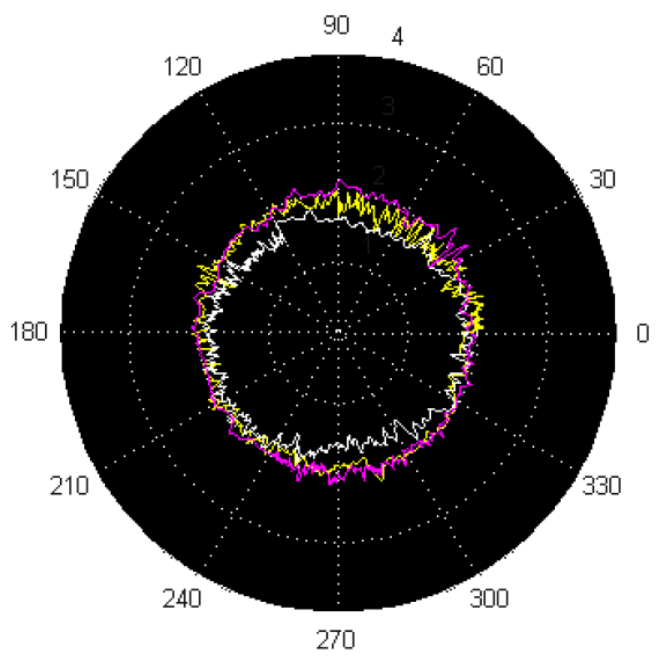

Figure 12: ERM Signal after1.0x10 6 cycles, revealing no contact between pad and disc. The three lines show the measured voltage drop across the individual pads and the disc. Each color represent one pad. The signal is mapped onto the disc making sure that a crack being formed will show up on all three signals on the same angular position. The radial amplitude of the signal shows the amount of solid contact between a pad and the disc.

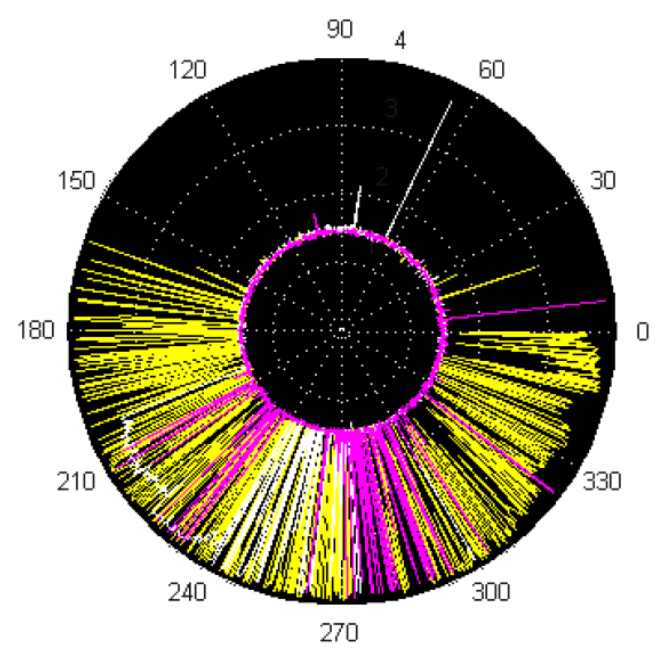

Figure 13 ERM Signal after $1.6 \times 10^{6}$ cycles reveals that contact between the pads and the disc is present

The development of one of the fatigue damages is shown for the 3 discrete times - Figure 9, Figure 10 and Figure 11. This damage spread across the entire disc after $2.0 \times 10^{6}$ cycles leading to a completely damaged disc. From Figure 9 -Figure 11 it can be seen how the damaged area evolves and destroys the running surface. Both cracks and smearing of the white metal can be observed indicating that the load carrying capacity is greatly reduced thus leading to larger pressures and lower separation between the pad and the disc, eventually leading to bearing failure.

\section{CONCLUSIONS / FUTURE WORK}

The test rig is capable of producing fatigue damages in white metal bearings. The damages are similar to damages observed in main bearings for large two stroke marine diesel engines. It is possible to monitor the development of cracks over time. The ERMsystem can be used for indicator of fatigue damages. The Rig is to be used for investigation of initiation and development of fatigue damages in white metal bearings as a function of different operating conditions - such as temperature, load, white metal thickness and load type. The rig will be used for investigating crack initiation and growth for different white metal coating compositions.

\section{REFERENCES /ACKNOWLEDGEMENT}

The authors wish to acknowledge the HERCULES-C project for the financial contribution to the current project. HERCULES-C is a part of the $7^{\text {th }}$ framework programme entitled 'Towards zero emission marine engines'. 
1. Peder Klit, Sebastian Persson, Anders Vølund :

Testing of Bearing Materials for Large Two-stroke

Marine Diesel Engines, Proceedings of the $12^{\text {th }}$

Pprime Workshop, Futoroscope France 2013

2. Koring, R. (2013). Changes in Bearing Technology.

Pennsylvania: SAE International 2012, ISBN: 978-

0-7680-7724-7

3. Anders Voelund \& Christian Felter, Experimental Investigation of Lubrication Regimes on Piston Ring - Cylinder Liner Contacts for Large Twostroke Engines, CIMAC2010, Paper 89 